Su, M., Young, B. and Gardner, L. (2014) "Testing and design of aluminum alloy cross-sections in compression.” Journal of Structural Engineering, ASCE, 140(9): 04014047.

\title{
TESTING AND DESIGN OF ALUMINUM ALLOY CROSS-SECTIONS IN COMPRESSION
}

\author{
by \\ Mei-Ni Su ${ }^{1}$, Ben Young, M.ASCE ${ }^{2}$ and Leroy Gardner ${ }^{3}$
}

ABSTRACT: Aluminum alloys are employed in a wide range of engineering applications and are gaining increasing usage in the construction sector, offering high strength-to-weight ratios and good durability. In this paper, a series of stub column tests on aluminum alloy box sections with and without internal cross stiffeners is carried out to investigate cross-section capacity and to explore the possible exploitation of strain hardening in design. All existing stub column test results from the literature were also collected. A database containing the results from 346 tests on aluminum alloy stub columns of box, channel and angle sections, with a wide range of crosssection slendernesses, was formed. The test strengths were compared with the design strengths predicted by the current American, Australian/New Zealand and European specifications. Furthermore, the test strengths were compared with those predicted by the deformation-based continuous strength method (CSM). Following reliability analyses, the design strengths predicted by the three current design specifications were found to be generally conservative, whereas the CSM offered improved design capacities, owing to its allowance for strain hardening.

KEY WORDS: Aluminum alloy; Angle; Buckling; Compressive capacities; Continuous strength method; Experimental investigation; Plain channel; Square and rectangular hollow sections; Structural Design; Stub columns; Testing 
${ }^{1} \mathrm{PhD}$ Candidate, Dept. of Civil Engineering, The Univ. of Hong Kong, Pokfulam, Hong Kong / Dept. of Civil and Environmental Engineering, Imperial College London, London SW7 2AZ, UK

${ }^{2}$ Professor, Dept. of Civil Engineering, The Univ. of Hong Kong, Pokfulam, Hong Kong. E-mail: young@hku.hk

${ }^{3}$ Professor, Dept. of Civil and Environmental Engineering, Imperial College London, London SW7 2AZ, UK. E-mail:

leroy.gardner@imperial.ac.uk

\section{INTRODUCTION}

The earliest examples of the use of aluminum alloys in building structures date back to the 1950s (Mazzolani, 1994). Since then, its use has spread to a wide range of construction applications such as building facades, roof systems, moving bridges and structures situated in humid environments. Key to expanding usage further is efficient structural design rules, underpinned by sound research. The focus of the present study is the compressive behavior of aluminum alloy structural sections, with an emphasis on the possible exploitation of strain hardening in design.

Over the past few decades a series of studies has been carried out to examine the loadbearing capacity of aluminum alloy structural elements. With an emphasis on the behavior of elements in compression, the key studies are introduced herein. Experimental investigations into the compressive capacity of aluminum alloy cross-sections have been carried out on different cross-section shapes, including H-sections (Bijlaard and Fisher, 1953), square and rectangular hollow sections (SHS/RHS) (Langseth and Hopperstad, 1997; Mazzolani et al., 1996, 1997a and 1998; Landolfo et al., 1999; Hassinen, 2000; Mennink, 2002; Zhu and Young, 2006a and 2008), channels (Mazzolani et al., 2001; Mennink, 2002) and angles (Mazzolani et al., 2011). The experimental structural performance data generated in these studies have been supplemented by the numerical findings of Mazzolani et al. (1997b), Mennink (2002) and Zhu and Young (2006b). These data are used herein to assess exiting design guidance for aluminum alloy cross-sections and to underpin the development of enhanced design provisions. 
There are a number of established international aluminum alloy structural design specifications, including the Aluminum Design Manual (AA, 2010), the Australian/New Zealand Standard (AS/NZS, 1997) and Eurocode 9 (EC9, 2007). These specifications provide accurate design rules for a range of structural components and applications though, in some areas, including the capacity of aluminum alloy compression members, design provisions are often overly conservative (Mennink, 2002; Zhu and Young, 2006a and 2008; Ashraf and Young, 2011). In the case of compact sections, this conservatism is largely attributed to the lack of account for strain hardening. This is recognized in Annex F of EC9, where an alternative design method that includes strain hardening is provided, leading to improved design efficiency. Besides these specifications, other relevant design methods include the direct strength method (DSM) and the continuous strength method (CSM). The DSM was initially proposed by Schafer and Peköz (1998) for the design of cold-formed steel structural members and is included in the AISI Specification for the design of cold-formed steel structural members (2004); the method was later applied to aluminum alloy structural members by Zhu and Young (2006b). The CSM (Gardner and Ashraf, 2006; Gardner, 2008; Gardner and Theofanous, 2008; Gardner et al., 2011; Afshan and Gardner, 2013) is a deformation-based design approach developed for stainless steel and carbon steel cross-sections which allows for the influence of strain hardening. The CSM is modified and extended herein to aluminum alloy structural members.

The experimental program conducted in this study consists of stub column tests on four types of extruded aluminum alloy sections: square hollow sections (SHS), rectangular hollow sections (RHS) and SHS/RHS with internal cross stiffeners. The experimental data generated in the present study, together with those gathered from previous tests conducted by other researchers, covers a large range of plate element width-to-thickness $(b / t)$ ratios. The experimental results are compared with the design compressive resistance predicted by the three aforementioned international specifications and the CSM. The CSM approach for aluminum alloy 
cross-section compressive capacity is also explained in detail, and reliability analyses are also presented.

\section{EXPERIMENTAL INVESTIGATION}

A series of 15 stub column tests on a range of aluminum alloy cross-sections was performed at the Structural Laboratory in the University of Hong Kong. The test specimens were manufactured by extrusion from grades 6061-T6 and 6063-T5 heat-treated aluminum alloys. The average measured cross-sectional dimensions and tensile material properties are shown in Table 1 for each test specimen. The symbols are defined, with reference to Figs. 1 and 2, as follows: $L$ is the stub column length, $E$ is the Young's modulus, $f_{y}$ is the material yield stress (taken as the $0.2 \%$ proof stress), $f_{u}$ is the material ultimate stress and $n$ is the exponent of the Ramberg-Osgood expression. The nominal lengths of the stub columns were selected as three times the larger crosssection dimension. After initial cutting, the ends of the specimens were milled flat to ensure a uniform distribution of applied loading.

The test specimens in this study were labeled according to the material strength and cross-section dimensions, as shown in Table 1 . For example, the label "H70×55×4.2C-R" defines the following specimen. The first letter " $\mathrm{H}$ ” refers to high strength aluminum alloy 6061-T6, while " $\mathrm{N}$ " refers to normal strength aluminum alloy 6063-T5; the nominal cross-section has dimensions of width $(70 \mathrm{~mm}) \times$ height $(55 \mathrm{~mm}) \times$ thickness $(4.2 \mathrm{~mm})$; if there is a “+” in front of the label, it means the hollow section has internal cross stiffeners of the same thickness as the outer walls of the section; the symbol "C" following the dimensions means a column compression test. Finally, if the test is repeated, a letter " $\mathrm{R}$ ” will be shown in the label.

The measured material properties of each specimen were determined by means of longitudinal tensile coupon tests and Webster hardness measurements. Coupon tests conformed to the Australian standard AS 1391 (AS, 2007) and the ASTM standard (ASTM, 1997). Webster 
hardness measurements were conducted according to the Standard Test Method for Indentation Hardness of Aluminum Alloys by Means of a Webster Hardness Gage (ASTM, 2010). The results highlight the different mechanical properties and behavior of the two tempers. The T5 temper has lower yield strength, considerable strain hardening, a lower hardness value but high ductility, whereas the T6 temper has higher yield strength, less pronounced strain hardening, a higher hardness value and lower ductility, as illustrated in Fig. 3.

Prior to testing, initial local geometric imperfections were measured around the four faces of selected stub columns at mid-height $-\mathrm{H} 64 \times 64 \times 3.0 \mathrm{C}, \mathrm{H} 95 \times 50 \times 10.5 \mathrm{C},+\mathrm{H} 95 \times 95 \times$ 4.3C-R and $+\mathrm{N} 95 \times 50 \times 10.5 \mathrm{C}$. The specimens were mounted on the bed of a milling machine, and measurements were taken by means of a digital displacement transducer, as shown in Fig. 4. Imperfections were recorded at $2 \mathrm{~mm}$ intervals; a typical measured imperfection profile is shown in Fig. 5.

A servo controlled hydraulic testing machine was used to apply compressive force by displacement control to the specimens at a constant rate of $0.4 \mathrm{~mm} / \mathrm{min}$. An initial load of $2 \mathrm{kN}$ was applied to the specimens to ensure full contact between the specimen and the upper and lower end plates. During testing, the machine was paused for 1.5 minutes prior to reaching the ultimate load, at ultimate load and before the end of the test. The purpose of the pause is to obtain the static curve. The columns were compressed between fixed ends, restrained against rotations, twisting and warping. The test configuration for specimen $\mathrm{H} 70 \times 55 \times 4.2 \mathrm{C}$ is shown in Fig. 6 . Three 25 mm-range LVDTs were used to measure the vertical deformation of the specimens. These were located between the upper and lower end plates. Strain gauges were attached at $10 \mathrm{~mm}$ intervals in the axial direction at mid-height of selected stub columns to determine the axial strain and to monitor local buckling. Since all sections are doubly symmetric, strain gauges were only adhered to one-quarter of the section perimeter. The applied load and readings from the LVDTs and strain gauges were recorded by a data logger at one second intervals during the tests. The experimental 
ultimate loads $P_{\text {exp }}$ are given in Table 2, where comparisons, which are discussed later, with the nominal compressive design strengths predicted by AA $\left(P_{A A}\right)$, AS/NZS $\left(P_{A S / N Z S}\right)$, EC9 $\left(P_{E C 9}\right)$ and the modified CSM $\left(P_{c s m}\right)$ are also given.

The load-deformation curves for all tested stub columns are shown in Figs. 7-9. All specimens failed by a combination of material yielding and inelastic local buckling, as shown in Fig. 10, though for some test specimens, evidence of global buckling was observed around the ultimate load level. Local buckling was more pronounced in the more slender cross-sections, as indicated by the non-uniform axial strain distributions shown for specimen $\mathrm{H} 64 \times 64 \times 3.0 \mathrm{C}$ in Fig. 11, compared to the more uniform distribution observed in the cross-stiffened $+\mathrm{H} 95 \times 95 \times 4.3 \mathrm{C}$ specimen, shown in Fig. 12. The delay of local buckling in the stockier sections enabled deformation into the strain hardening range and, the attainment of loads significantly greater than the yield load $A f_{y}$. It should be noted that in some cases, ultimate capacities greater than $A f_{u}$ were observed, which are achieved due to the increased cross-sectional areas arising from the Poisson effect in the compressed sections.

\section{COMPARISON OF TEST STRENGTHS WITH DESIGN STRENGTHS}

Test data on aluminum alloy stub columns from the literature have been combined with those generated in the present study and used to evaluate the compressive strengths of crosssections predicted by current standards. A total of 346 experiments have been considered, with a range of section types: 110 SHS/RHSs, 203 plain channel sections and 33 angle sections. The experimental strengths $P_{\text {exp }}$ are compared with the nominal strengths (unfactored design strengths) predicted by the Aluminum Design Manual (AA, 2010), the Australia/New Zealand Standard (AS/NZS, 1997) and Eurocode 9 (EC9, 2007). The comparisons were performed using the measured material properties and geometries with all safety factors set to unity, and the results are shown in Figs. 13-15. 
The Aluminum Design Manual (AA, 2010) provides design rules for aluminum alloy stub columns, in which the resistance of stocky sections is defined as the yield stress multiplied by the gross cross-sectional area, while a reduced stress is used for slender sections (Fig. 16). The AS/NZS (1997) design provisions are the same as AA (2010), except with a reduction coefficient for compression members (Fig. 16). The mean ratios of experimental to predicted ultimate loads for the AA standard $\left(P_{\text {exp }} / P_{A A}\right)$ and the AS/NZS standard $\left(P_{\text {exp }} / P_{A S / N Z S}\right)$ for non-slender specimens $\left(\bar{\lambda}_{p} \leq 0.68\right)$ were 1.12 and 1.24 with corresponding coefficients of variation (COV) of 0.110 and 0.123 , while mean values were 1.19 and 1.28 with COV of 0.251 and 0.250 when comparing to all specimens (see Table 3 and Figs. 13-14). EC9 limits the resistance of nonslender sections to the yield load and employs an effective thickness concept for slender sections, but provides an alternative approach in Annex $\mathrm{F}$ which utilizes the ultimate stress $f_{u}$ for Class 1 sections (Fig. 16). All comparisons made herein with EC9 use the more favorable Annex F approach. The EC9 Annex F (2007) comparisons with the test results gave a mean value of $P_{\text {exp }} / P_{E C 9}$ of 1.10 and a corresponding COV of 0.902 for non-slender specimens with $\bar{\lambda}_{p} \leq 0.68$, and a mean value of 1.17 and a corresponding COV of 0.169 for all specimens (see Table 3 and Fig. 15). Table 3 summarizes the comparisons of the three specifications: overall, EC9 Annex F (2007) gave the most accurate predictions of stub column compression capacity, while AS/NZS (1997) provided the most conservative design strengths. The conservatism was attributed primarily to the ability of the cross-sections to achieve capacities greater than the yield load as a result of strain hardening. The failure modes predicted by the three specifications are all material yielding (with, in the case of Annex F of EC9, allowance for strain hardening), which generally coincides with the observed failure modes. 


\section{THE CONTINUOUS STRENGTH METHOD}

\section{General}

The continuous strength method (CSM) is a deformation based design framework that allows for the beneficial influence of strain hardening. The two main features of the method are (1) a base curve defining the level of strain that a cross-section can tolerate before failure, as a function of cross-section slenderness and (2) a strain hardening material model. These two components have been established for structural carbon steel (Gardner and Theofanous, 2008; Gardner et al., 2011) and stainless steel (Afshan and Gardner, 2013) in previous studies. Building on recent proposals (Gardner and Ashraf, 2006; Ashraf and Young, 2011), development of a base curve and a suitable strain hardening material model for aluminum alloys is described in the following sections.

\section{Base curve}

The CSM base curve defines the level of strain that a cross-section can carry as a function of its local slenderness. The curve provides a continuous relationship between cross-section deformation capacity and cross-section slenderness. It was developed based on both stub column tests and four-point bending tests on carbon steel, stainless steel as well as aluminum alloy crosssections.

In the CSM, the cross-section slenderness $\bar{\lambda}_{p}$ is defined in non-dimensional form as the square root of the ratio of the yield stress $f_{y}$ to the elastic buckling stress $\sigma_{c r}$ of the cross-section (Eq. 1). The elastic buckling stress can be determined according to analytical approximations (e.g. Seif and Schafer (2010)) or a numerical approach, such as CUFSM (Li and Schafer, 2010). Both take into account the effects of element interaction instead of only considering the slenderness of the most slender individual element; in this study the software CUFSM (Li and Schafer, 2010) 
was used. Conservatively, element interaction can be ignored and cross-section slenderness taken as that of it most slender constituent plate element. Cross-section deformation capacity $\varepsilon_{c s m} / \varepsilon_{y}$ is also defined in a normalized form as the strain at ultimate load $\varepsilon_{l b}$ minus $0.2 \%$ plastic strain, divided by the yield strain $\varepsilon_{y}$, where $\varepsilon_{y}=f_{y} / E$. Note that subtraction of the $0.2 \%$ plastic strain from the deformation capacity enables compatibility with the bilinear material model described in the following section. For stub columns, the deformation capacity is determined from the end shortening at the ultimate load $\delta_{u}$ and the stub column length (for sections reaching the yield load) or ultimate load (for sections failing before reaching the yield load), as given by Eqs. 2 and 3 respectively, where $P_{y}=A f_{y}$ is the yield load of the stub columns.

$$
\begin{array}{ll}
\bar{\lambda}_{p}=\sqrt{f_{y} / \sigma_{C r}} & \\
\frac{\varepsilon_{C S m}}{\varepsilon_{y}} \frac{\varepsilon_{l b^{-0.002}}}{\varepsilon_{y}}=\frac{\delta_{u} / L-0.002}{\varepsilon_{y}} & \text { for } P_{\exp } \geq P_{y} \quad \text { and } \bar{\lambda}_{p} \leq 0.68 \\
\frac{\varepsilon_{C S m}}{\varepsilon_{y}}=\frac{P_{\exp }}{P_{y}} & \text { for } P_{\exp }<P_{y} \text { or } \bar{\lambda}_{p}>0.68
\end{array}
$$

The applicability of the CSM is limited to $\bar{\lambda}_{p} \leq 0.68$. This limit indicates the transition between slender sections (i.e. those that fail below the yield limit) and non-slender sections (i.e. those that fail beyond the yield limit), and is shown in Fig 17. This figure shows the results of stub column tests on square hollow sections (SHS), rectangular hollow sections (RHS), channels and angles, where the test ultimate loads have been normalized by the cross-section yield loads. It reveals that non-slender sections $\left(\bar{\lambda}_{p} \leq 0.68\right)$ can achieve capacities beyond the yield limit owing to strain hardening. The experimental data within the application range, which failed by local buckling, are plotted in Fig. 18 on a graph of deformation capacity versus cross-section slenderness, together with the base curve (Eq. 4). The two upper bounds to the CSM strain, 
namely $15 \varepsilon_{y}$ and $0.5 \varepsilon_{u}$, relate to limiting plastic deformations and avoiding material fracture, respectively.

$$
\frac{\varepsilon_{C S m}}{\varepsilon_{y}}=\frac{0.25}{\bar{\lambda}_{p}^{3.6}} \quad \text { but } \quad \frac{\varepsilon_{C S m}}{\varepsilon_{y}} \leq \operatorname{lesser}\left(15, \frac{0.5 \varepsilon_{u}}{\varepsilon_{y}}\right) \quad \text { for } \bar{\lambda}_{p} \leq 0.68
$$

The existing base curve (Eq. 4), developed for carbon steel and stainless steel, may be seen to also provide a good prediction of deformation capacity for aluminum alloy cross-sections.

\section{Material Model \\ General}

The CSM employs an elastic, linear hardening material model, with the strain hardening modulus varying with material grade. The slope of the linear hardening region is defined on the basis of passing through two fixed points - the $0.2 \%$ proof stress and corresponding strain $\left(f_{y}\right.$, $\left.\varepsilon_{y}+0.002\right)$ and the ultimate tensile stress at 0.5 of the ultimate strain plus $0.2 \%$ strain $\left(f_{u}\right.$, $0.5 \varepsilon_{u}+0.002$ ). Addition of the $0.2 \%$ strain to the second point during the derivation of the model allows the resulting line to be translated to the left by $0.2 \%$ strain, with no change in slope, such that the final model passes through $\left(f_{y}, \varepsilon_{y}\right)$ and $\left(f_{u}, 0.5 \varepsilon_{u}\right)$. The development of this material model and the choice of parameters are described in the following sub-sections.

\section{Ultimate strain prediction}

The strain at the ultimate tensile stress $\varepsilon_{u}$ is a key factor in the material model, particularly in determining the slope of the strain hardening region. However, in most cases, this value is not reported by manufacturers and thus is not readily available to designers. EC9 (2007) includes a method to predict the ultimate material strain, as given by Eqs. 5 and 6. A comparison between the EC9 (2007) predictive model and collected experimental data for $\varepsilon_{u}$ (Langseth and 
Hopperstad, 1997; Meon et al., 1999; Zhu and Young, 2006a; Su et al., 2012) is shown in Fig. 19. The experimental values of ultimate strain $\varepsilon_{u, t e s t}$ may be seen to be generally lower than the

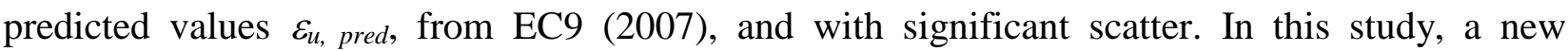
expression (Eq. 7) is proposed for the prediction of ultimate strain. It follows a similar format to the ultimate strain prediction equation for stainless steel in EN1993-1-4 (2006); the model coefficients were calibrated based on the coupon test results by means of least squares regression. Note that no data with $f_{u} / f_{y} \leq 1.01$ was used in the development of Eq. 7; therefore this may be considered as the limit of applicability of Eq. 7. Significantly improved predictions of ultimate strain may be seen in Fig. 19.

$$
\begin{array}{ll}
\varepsilon_{u}=0.3-0.22\left(f_{y} / 400\right) & \text { for } f_{y}<400 \mathrm{~N} / \mathrm{mm}^{2} \\
\varepsilon_{\mathrm{u}}=0.08 & \text { for } f_{y} \geq 400 \mathrm{~N} / \mathrm{mm}^{2} \\
\varepsilon_{\mathrm{u}}=0.13\left(1-f_{y} / f_{u}\right)+0.06 &
\end{array}
$$

\section{Strain hardening slope}

The CSM bi-linear material model contains two parts: the initial elastic part and the linear hardening part (Fig. 20). The elastic part is defined by the Young's Modulus of the material. The strain hardening region has a strain hardening slope $E_{\text {sh }}$, defined by Eq. 8. A suitable expression for defining $E_{s h}$ was initially explored by considering two end points as $\left(f_{y}, \varepsilon_{y}+0.002\right)$ and $\left(f_{u}\right.$, $x \varepsilon_{u}+0.002$ ), where $x$ is the proportion of ultimate strain. With $0.2 \%$ plastic strain deduced from both end points, the resulting material model passes through $\left(f_{y}, \varepsilon_{y}\right)$ and $\left(f_{u}, x \varepsilon_{u}\right)$. The value of $x$ was determined from experimental data (Zhu and Young, 2006a; Su et al., 2012) with two considerations. The first consideration was to obtain an accurate fit to measured $\sigma-\varepsilon$ curves; this 
was achieved through least square regression. The second was to ensure that the simplified model did not over-predict any experimental $\sigma-\varepsilon$ curves to a significant degree. A value of $x=0.5$ was found to satisfy both considerations, with a maximum over-prediction in stress $\Delta d$ of less than $5 \%$ when compared to the collected set of 33 measured $\sigma-\varepsilon$ curves. Note that lower values of $x$ provided an improved least square fit to the collected test data but higher maximum overpredictions, while the opposite was found for higher values of $x$. In addition to providing a suitably accurate representation of experimental data, the value of $x=0.5$ also matches that given in Annex E of EC9 (2007). The proposed CSM material model is therefore consistent with this existing provision. A typical comparison between a measured $\sigma-\varepsilon$ curve and the CSM material model is shown in Fig. 20.

$$
E_{s h}=\frac{f_{u}-f_{y}}{0.5 \varepsilon_{u}-\varepsilon_{y}}
$$

\section{Design procedure}

The resulting CSM design procedure for determining the compressive strength of aluminum alloy cross-sections may be summarized in the following three steps:

(1) Calculate the cross-section slenderness $\bar{\lambda}_{p}$ :

$\bar{\lambda}_{p}=\sqrt{f_{y} / \sigma_{c r}}$

where $\sigma_{c r}$ is the elastic buckling stress of the cross-section, which may be determined numerically using programs such as CUFSM (Li and Schafer, 2010) or using simplified analytical expressions (Seif and Schafer, 2010). Alternatively, $\bar{\lambda}_{p}$ may be determined on an element by element basis, by taking the cross-section slenderness as that of its most slender constituent plate. 
(2) Determine the level of strain that the cross-section can endure $\varepsilon_{c s m}$ from the base curve:

$\frac{\varepsilon_{C S m}}{\varepsilon_{y}}=\frac{0.25}{\bar{\lambda}_{p}^{3.6}} \quad$ but $\frac{\varepsilon_{C S m}}{\varepsilon_{y}} \leq$ lesser $\left(15, \frac{0.5 \varepsilon_{u}}{\varepsilon_{y}}\right) \quad$ for $\bar{\lambda}_{p} \leq 0.68$

(3) Finally, the corresponding limiting stress $f_{c s m}$ and cross-section compression strength $P_{c s m}$ can be found from:

$f_{c s m}=f_{y}+E_{s h}\left(\varepsilon_{c s m}-\varepsilon_{y}\right)$

and

$P_{c s m}=A f_{c s m}$

Comparisons between experimental cross-section capacities in compression and those predicted by the CSM are presented in the following section.

\section{Comparison of Test Results with Design Strengths}

In this section, the CSM is used to predict the strengths of stub columns with a global

slenderness $\bar{\lambda}=\sqrt{A f_{y} / P_{C r}}$, where $P_{c r}$ is the overall elastic buckling load of the member in compression, less than 0.2, such that global buckling is discounted. Comparisons are also limited to non-slender cross-sections, with the local slenderness $\bar{\lambda}_{p}$ not greater than 0.68 . The comparisons are presented in Fig. 21 and Table 3. Overall, a mean prediction $P_{\text {exp }} / P_{c s m}$ of 1.04 with a COV of 0.086 is achieved, which represents improved accuracy and reduced scatter in comparison with all considered existing approaches. 


\section{RELIABILITY ANALYSIS}

The reliability of the CSM and the three considered design codes for aluminum alloy stub columns is evaluated by means of statistical analysis in this section. Reliability analysis uses the safety index $\beta$ as an indicator of the design safety level. The calculation procedure adopted is that detailed in the Aluminum Design Manual (AA, 2010). The reliability index is calculated in accordance with Clause 1.3.2 of Appendix 1, Part I in AA (2010), where the mean values and COVs for material properties and fabrication variables are taken as $M_{m}=1.10$ (for behavior governed by the yield stress) $/ 1.00$ (for behavior governed by the ultimate stress), $F_{m}=1.00, V_{M}$ $=0.06$, and $V_{F}=0.05$. The statistical parameters $P_{m}$ and $V_{p}$ are the mean value and COV of the experimental-to-predicted load ratios, and are included in Table 3. The correction factor $C_{P}$ given by AA (2010) is used to account for the influence of a small number of tests. A load combination of 1.2DL + 1.6LL (where DL and LL signify Dead loads and Live loads, respectively) is used for AA (2010), while 1.25DL + 1.50LL and 1.35DL + 1.50LL are used for AS/NZS (1997) and EC9 (2007), respectively. The resistance factor $\phi$ depends on the structural scenario being addressed and the design specification under consideration. In the case of aluminum alloy stub columns, $\phi$ is assumed as 0.90, 0.85 and 0.91 for AA (2010), AS/NZS (1997) and EC9 (2007), respectively. The minimum reliability index for aluminum alloy columns is 2.5, as required in AA (2010) and AS1170-0 (2002). In this study, a target reliability index 2.5 is also applied to EC9 (2007). Thus, if the reliability index is greater than or equal to 2.5 , the design method is deemed to be reliable. Furthermore, in order to have a direct comparison among different design approaches, a constant resistant factor $\phi_{2}=0.90$ and a load combination of 1.2DL+1.6LL, as specified in AA (2010), were used to calculate the reliability index $\beta_{2}$ for AA (2010), AS/NZS (1997), EC9 (2007) and the CSM.

The reliability indices $\beta$ of the three current specifications (for specimens with $\bar{\lambda}_{p}<0.68$ ) are 2.86, 3.28 and-2.69 for AA (2010), AS/NZS (1997) and EC9 (2007), respectively; however, 
the reliability indices become 2.32, 2.61 and 2.54 for the aforementioned specifications when considering all specimens. That is to say, only AS/NZS (1997) and EC9 (2007) is reliable for aluminum alloy stub column capacity prediction. In the direct comparison for all specimens, with $\phi=0.90$ and a load combination of $1.2 \mathrm{DL}+1.6 \mathrm{LL}$, EC9 $\left(\beta_{2}=2.67\right)$ has the highest reliability level, whereas the AA $\left(\beta_{2}=2.32\right)$ has the lowest value. Considering only the specimens within the CSM range of application (i.e. $\bar{\lambda}_{\mathrm{p}} \leq 0.68$ ), a reliability index of 2.50 is obtained for the CSM approach, which is equal to the target value of 2.50. Thus, it may be concluded that the CSM can provide reliable design resistance predictions for aluminum alloy stub columns, using a resistance factor $\phi=0.90$.

\section{CONCLUSIONS}

A test program on aluminum alloy square and rectangular hollow section stub columns with and without internal cross stiffeners has been presented. Two aluminum alloys, namely 6061-T6 and 6063-T5, were used in the investigation. The experimental data obtained in this study, together with previous test results from other researchers, totaling 346 aluminum alloy stub columns of different alloy tempers and section shapes (i.e. SHS/RHS, plain channel and angle), were analyzed. The results were used to verify the applicability of the CSM base curve to aluminum alloy cross-sections and to develop a simple material model to represent the strain hardening behavior of the material. The latter included the proposal of a revised expression for the prediction of ultimate strain. A comparison of the test results with the design strengths of the American, Australian/New Zealand and European specifications, as well as the continuous strength method (CSM) for aluminum structures, has been performed. It is found that the design predictions from the three design codes are more conservative for stocky cross-sections due to the occurrence of strain hardening. The design strengths predicted by the continuous strength method, which allows for the systematic exploitation of strain hardening, were found to be more accurate 
and more consistent than existing design methods. The reliability of the CSM with a resistance factor of $\phi=0.9$ was also demonstrated.

\section{ACKNOWLEDGEMENTS}

The research work described in this paper was supported by a grant from The University of Hong Kong under the seed funding program for basic research. The authors are also grateful to Mr Yiran Li for his assistance in the experimental program as part of his final year undergraduate research project at The University of Hong Kong.

\section{NOTATION}

$$
\begin{array}{ll}
A & =\text { Cross-section area } \\
B & =\text { Section width } \\
b & =\text { Flat width of flange } \\
C O V & =\text { Coefficient of variation } \\
C_{p} & =\text { Correction factor } \\
E & =\text { Young's modulus } \\
E_{s h} & =\text { Strain hardening modulus } \\
f_{c s m} & =\text { CSM limiting stress } \\
f_{y} & =\text { Yield strength, taken as the } 0.2 \% \text { proof strength } \\
f_{u} & =\text { Ultimate tensile strength } \\
F_{m} & =\text { Mean value of fabrication variables } \\
H & =\text { Section depth } \\
h & =\text { Flat depth of web } \\
M_{m} & =\text { Meanber length value of material factor } \\
&
\end{array}
$$




$$
\begin{aligned}
& n \quad=\text { Exponent in Ramberg-Osgood expression } \\
& P_{A A} \quad=\text { Collapse load predicted by AA (2010) } \\
& P_{\text {AS/NZS }}=\text { Collapse load predicted by AS/NZS (1997) } \\
& P_{c s m}=\text { Collapse load predicted by the CSM } \\
& P_{c r} \quad=\text { Euler buckling load } \\
& P_{E C 9} \quad=\text { Collapse load predicted by EC9 (2007) } \\
& P_{\text {exp }} \quad=\text { Test ultimate load } \\
& P_{m} \quad=\text { Mean value of test-to-predicted load ratios } \\
& P_{y} \quad=A f_{y} \text {, the yield load } \\
& t \quad=\text { Wall thickness } \\
& V_{F} \quad=\text { Coefficient of variation of fabrication factor; } \\
& V_{M} \quad=\text { Coefficient of variation of material factor; } \\
& V_{P} \quad=\text { Coefficient of variation of test-to-predicted load ratios; } \\
& \beta \quad=\text { Reliability index } \\
& \delta_{u} \quad=\text { End shortening at ultimate load } \\
& \varepsilon_{c s m} \quad=\text { CSM limiting strain } \\
& \varepsilon_{l b} \quad=\text { Local buckling strain, equal to stub column end shortening divided by stub column } \\
& \text { length at ultimate load } \\
& \varepsilon_{u} \quad=\text { Strain at ultimate tensile stress } \\
& \varepsilon_{y} \quad=\text { Yield strain }\left(f_{y} / E\right) \\
& \phi \quad=\text { Resistance factor } \\
& \bar{\lambda}_{p} \quad=\text { Cross-section/plate slenderness } \\
& \sigma_{c r} \quad=\text { Elastic buckling stress }
\end{aligned}
$$




\section{REFERENCES}

Afshan, S. and Gardner, L. (2013) “The continuous strength method for structural stainless steel design” Thin-Walled Structures, 68(2013): 42-49.

Aluminum Association (AA). (2010). Aluminum design manual. Washington, D.C.

American Iron and Steel Institute (AISI). (2004) AISI Supplement 2004 to the North American Specification for the Design of Cold- Formed Steel Structural Members, 2001 Edition: Appendix 1, Design of Cold-Formed Steel Structural Members Using Direct Strength Method., Washington, D.C., SG05-1.

American Society for Testing and Materials (ASTM). (1997). "Standard test methods for tension testing of metallic materials.” E 8M-97, West Conshohocken, Pa.

American Society for Testing and Materials (ASTM). (2010). "Standard Test method for indentation hardness of aluminum alloys by means of a Webster hardness gage.” ASTM B647-10, West Conshohocken, Pa.

Ashraf, M. and Young, B. (2011). "Design formulations for non-welded and welded aluminum stub columns using Continuous Strength Method.” Engineering Structures. 33(12): 31973207

Australian Standard (AS). (2002). "Structural design actions - General principles.” AS 11700:2002, Standards Association of Australia, Sydney, Australia.

Australian Standard (AS). (2007). "Methods for tensile testing of metals." AS 1391-2007, Standards Association of Australia, Sydney, Australia. 
Australian/New Zealand Standard (AS/NZS). (1997). “Aluminum structures part 1: Limit state design.” AS/NZS 1664.1:1997, Standards Australia, Sydney, Australia.

Bijlaard, P. P. and Fisher, G. P. (1953). “Column strength of H-sections and square tubes in post buckling range of component plates.” National Advisory Committee for Aeronautics Technical Note 2994, Washington.

European Committee for Standardization (EC3). (2006) "Eurocode 3: Design of steel structuresPart 1-4: General rules - Supplementary rules for stainless steels”. EN 1993-1-4:2006, CEN.

European Committee for Standardization (EC9). (2007). "Eurocode 9: Design of aluminum structures_-Part 1-1: General rules_-General rules and rules for buildings.” BS EN 19991-1:2007, CEN.

Gardner, L. and Ashraf, M. (2006). "Structural design for non-linear metallic materials." Engineering Structures 28(6):926-934.

Gardner, L. (2008). “The continuous strength method.” Proceedings of the Institution of Civil Engineers, Structures \& Buildings 161(3):127-133.

Gardner, L. and Theofanous, M. (2008). "Discrete and continuous treatment of local buckling in stainless steel elements.” Journal of Constructional Steel Research 64(11): 1207-1216.

Gardner, L., Wang, F. and Liew, A. (2011). "Influence of strain hardening on the behavior and design of steel structures.” International Journal of Structural Stability and Dynamics 11(5): 855-875. 
Hassinen, P. (2000). “Compression strength of aluminum columns - Experimental and numerical studies.” Proceedings of the 3rd International Conference on Coupled Instabilities of Metal Structures, 241-248, CIMS’2000, ICP, London, UK.

Landolfo, R., Piluso, V., Langseth, M. and Hopperstad, O.S. (1999). “EC9 provisions for flat internal elements: comparison with experimental results.” Light-Weight Steel and Aluminum Structures, 515-522.

Langseth, M. and Hopperstad, O. S. (1997). "Local buckling of square thin-walled aluminum extrusions.” Thin- Walled Structures 27(1):117-126.

Li, Z. and Schafer, B.W. (2010) "Buckling analysis of cold-formed steel members with general boundary conditions using CUFSM: conventional and constrained finite strip methods.” Proceedings of the 20th Int;l. Spec. Conf. on Cold-Formed Steel Structures, 17-31, St. Louis, MO. (Nov, 2010).

Mazzolani, F.M. (1994), Aluminum alloy structures $2^{\text {nd }}$. E\&FN Spon Press.

Mazzolani, F.M., Faella, C., Piluso, V. and Rizzano, G. (1996), “Experimental analysis of aluminum alloy SHS-members subjected to local buckling under uniform compression.” Proceeding of 5th International Colloquium on Structural Stability, 475-488, SSRC, Rio de Janeiro, Brazil (Apr, 1996).

Mazzolani, F. M., Faella, C., Piluso, V. and Rizzano, G. (1997a). “Local buckling of aluminum alloy RHS-members: experimental analysis.” Proceeding of XVI Congresso C.T.A., Italian Conference on Steel Construction, 1-12, Collegio dei Tecnici dell'Acciaio, Ancona (Oct, 1997). 
Mazzolani, F.M., Piluso, V. and Rizzano, G. (1997b), “Numerical simulation of aluminum stocky hollow members under uniform compression.” Proceeding of 5th International Colloquium on Stability and Ductility of Steel Structures, SDSS'97, Nagoya, Japan (Jul, 1997).

Mazzolani, F.M., Faella, C., Piluso, V. and Rizzano, G. (1998). "Local buckling of aluminum members: experimental analysis and cross-sectional classification.” Department of Civil Engineering, University of Salerno, Italy.

Mazzolani, F. M., Piluso, V. and Rizzano, G. (2001), “Experimental analysis of aluminum alloy channels subjected to local buckling under uniform compression.” Proceeding of C.T.A., Italian Conference on Steel Construction. ACS, 1-10, Acai Servizi, Milano, Italy (Sep, 2001).

Mazzolani, F.M., Piluso, V., and Rizzano, G. (2011), “Local buckling of aluminum alloy angles under uniform compression.” Journal of Structural Engineering, ASCE 137(2):173-184.

Mennink, J. (2002). Cross-Sectional Stability of Aluminum Extrusions: Prediction of the Actual Local Buckling Behavior. The Netherlands.

Moen, L.A., Hopperstad, O.S. and Langseth M. (1999). “Rotational capacity of aluminium beams under moment gradient. I: experiments.” Journal of Structural Engineering, ASCE 125(8): 910-920.

Su, M., Young, B. and Gardner, L. (2012) “Compression tests of aluminium alloy cross-sections”, Proceedings of the $13^{\text {th }}$ International Symposium Tubular Structures pp. 501-508 (London, 2012) 
Schafer, B.W. and Peköz, T. (1998). “Direct strength prediction of cold-formed steel members using numerical elastic buckling solutions.” Proceeding of 14th Int. specialty conference on cold-formed steel structures, 69 - 76. University of Missouri-Rolla, Rolla, Mo.

Seif, M. and Schafer, B.W. (2010). "Local buckling of structural steel shapes.” Journal of Constructional Steel Research 66(10): 1232-1247.

Zhu, J.H., and Young, B. (2006a). “Tests and design of aluminum alloy compression members.” Journal of Structural Engineering, ASCE 132(7):1096-1107.

Zhu, J.H. and Young, B. (2006b). “Aluminum alloy tubular columns - Part II: parametric study and design using direct strength method.” Thin-Walled Structures 44(9):969-985.

Zhu, J.H. and Young, B. (2008). "Behavior and design of aluminum alloy structural members.” Advanced Steel Construction 4(2):158-172. 
Table 1. Measured stub column dimensions and material properties from tensile coupon tests

\begin{tabular}{|c|c|c|c|c|c|c|c|c|c|}
\hline Specimen & $\begin{array}{c}B \\
(\mathrm{~mm})\end{array}$ & $\begin{array}{c}H \\
(\mathrm{~mm})\end{array}$ & $\begin{array}{c}t \\
(\mathrm{~mm})\end{array}$ & $\begin{array}{c}L \\
(\mathrm{~mm})\end{array}$ & $\begin{array}{c}E \\
(\mathrm{GPa})\end{array}$ & $\begin{array}{c}f_{y} \\
(\mathrm{MPa})\end{array}$ & $\begin{array}{c}f_{u} \\
(\mathrm{MPa})\end{array}$ & $n$ & $\begin{array}{l}\text { Webster } \\
\text { hardness }\end{array}$ \\
\hline $\mathrm{H} 64 \times 64 \times 3.0 \mathrm{C}$ & 63.9 & 63.9 & 2.81 & 191.1 & 66 & 234 & 248 & 12 & 13 \\
\hline $\mathrm{H} 64 \times 64 \times 3.0 \mathrm{C}-\mathrm{R}$ & 63.9 & 63.9 & 2.85 & 191.5 & 66 & 234 & 248 & 12 & 13 \\
\hline $\mathrm{H} 70 \times 55 \times 4.2 \mathrm{C}$ & 69.9 & 54.9 & 4.08 & 209.8 & 65 & 193 & 207 & 22 & 12 \\
\hline $\mathrm{H} 70 \times 55 \times 4.2 \mathrm{C}-\mathrm{R}$ & 69.9 & 54.9 & 4.09 & 209.9 & 65 & 193 & 207 & 22 & 12 \\
\hline $\mathrm{H} 95 \times 50 \times 10.5 \mathrm{C}$ & 94.8 & 49.7 & 10.36 & 284.9 & 71 & 229 & 242 & 11 & 12 \\
\hline $\mathrm{H} 120 \times 70 \times 10.5 \mathrm{C}$ & 119.9 & 69.9 & 10.39 & 360.0 & 69 & 226 & 238 & 10 & 12 \\
\hline $\mathrm{H} 120 \times 120 \times 9.0 \mathrm{C}$ & 120.0 & 120.0 & 8.91 & 360.2 & 65 & 225 & 234 & 13 & 12 \\
\hline $\mathrm{N} 95 \times 50 \times 10.5 \mathrm{C}$ & 94.9 & 49.7 & 10.37 & 285.2 & 69 & 179 & 220 & 10 & 11 \\
\hline $\mathrm{N} 120 \times 70 \times 10.5 \mathrm{C}$ & 119.9 & 69.8 & 10.45 & 360.9 & 71 & 139 & 194 & 9 & 11 \\
\hline $\mathrm{N} 120 \times 120 \times 9.0 \mathrm{C}$ & 120.0 & 120.0 & 8.92 & 361.3 & 69 & 181 & 228 & 9 & 11 \\
\hline +H95×95×4.3C & 95.4 & 95.3 & 4.17 & 284.8 & 67 & 228 & 240 & 12 & 12 \\
\hline$+\mathrm{H} 95 \times 95 \times 4.3 \mathrm{C}-\mathrm{R}$ & 95.4 & 95.3 & 4.17 & 284.8 & 67 & 228 & 240 & 12 & 12 \\
\hline$+\mathrm{H} 120 \times 70 \times 10.5 \mathrm{C}$ & 120.1 & 69.9 & 10.27 & 360.0 & 69 & 215 & 229 & 8 & 10 \\
\hline$+\mathrm{H} 120 \times 70 \times 10.5 \mathrm{C}-\mathrm{R}$ & 120.0 & 69.9 & 10.26 & 360.0 & 69 & 215 & 229 & 8 & 10 \\
\hline$+\mathrm{N} 95 \times 50 \times 10.5 \mathrm{C}$ & 94.6 & 49.7 & 10.03 & 284.4 & 72 & 151 & 181 & 11 & 8 \\
\hline
\end{tabular}

Table 2. Comparison of stub column test results with different design methods

\begin{tabular}{|c|c|c|c|c|c|c|}
\hline Specimen & $b / t$ & $\begin{array}{l}P_{\text {Exp }} \\
(\mathrm{kN})\end{array}$ & $\frac{P_{E x p}}{P_{A A}}$ & $\frac{P_{E x p}}{P_{A S / N Z S}}$ & $\frac{P_{E x p}}{P_{E C 9}}$ & $\frac{P_{\text {Exp }}}{P_{c s m}}$ \\
\hline $\mathrm{H} 64 \times 64 \times 3.0 \mathrm{C}$ & 20.7 & 164.2 & 1.02 & 1.15 & 1.02 & 1.02 \\
\hline $\mathrm{H} 64 \times 64 \times 3.0 \mathrm{C}-\mathrm{R}$ & 20.4 & 165.4 & 1.02 & 1.14 & 1.02 & 1.01 \\
\hline $\mathrm{H} 70 \times 55 \times 4.2 \mathrm{C}$ & 15.1 & 196.2 & 1.07 & 1.20 & 1.07 & 1.00 \\
\hline $\mathrm{H} 70 \times 55 \times 4.2 \mathrm{C}-\mathrm{R}$ & 15.1 & 196.9 & 1.02 & 1.20 & 1.02 & 1.01 \\
\hline $\mathrm{H} 95 \times 50 \times 10.5 \mathrm{C}$ & 7.1 & 626.2 & 1.07 & 1.20 & 1.01 & 1.01 \\
\hline $\mathrm{H} 120 \times 70 \times 10.5 \mathrm{C}$ & 9.5 & 862.5 & 1.09 & 1.22 & 1.03 & 1.03 \\
\hline $\mathrm{H} 120 \times 120 \times 9.0 \mathrm{C}$ & 11.5 & 981.5 & 1.10 & 1.23 & 1.06 & 1.06 \\
\hline $\mathrm{N} 95 \times 50 \times 10.5 \mathrm{C}$ & 7.2 & 609.8 & 1.45 & 1.63 & 1.15 & 1.09 \\
\hline $\mathrm{N} 120 \times 70 \times 10.5 \mathrm{C}$ & 9.5 & 736.9 & 1.50 & 1.68 & 1.10 & 1.22 \\
\hline $\mathrm{N} 120 \times 120 \times 9.0 \mathrm{C}$ & 11.5 & 811.1 & 1.13 & 1.27 & 0.92 & 0.91 \\
\hline +H95×95×4.3C & 9.9 & 585.6 & 1.21 & 1.36 & 1.10 & 1.09 \\
\hline$+\mathrm{H} 95 \times 95 \times 4.3 \mathrm{C}-\mathrm{R}$ & 9.9 & 547.2 & 1.13 & 1.27 & 1.02 & 1.02 \\
\hline$+\mathrm{H} 120 \times 70 \times 10.5 \mathrm{C}$ & 4.4 & 1164.3 & 1.16 & 1.30 & 1.05 & 1.04 \\
\hline$+\mathrm{H} 120 \times 70 \times 10.5 \mathrm{C}-\mathrm{R}$ & 4.4 & 1174.4 & 1.17 & 1.32 & 1.06 & 1.05 \\
\hline$+\mathrm{N} 95 \times 50 \times 10.5 \mathrm{C}$ & 3.2 & 664.8 & 1.66 & 1.86 & 1.37 & 1.11 \\
\hline
\end{tabular}


Table 3. Summary of comparisons between stub column test results and design strengths

\begin{tabular}{lrrrr}
\hline & $\frac{P_{E x p}}{P_{A A}}$ & $\frac{P_{E x p}}{P_{A S / N Z S}}$ & $\frac{P_{E x p}}{P_{E C 9}}$ & $\frac{P_{E x p}}{P_{c s m}}$ \\
\hline Number of specimens & $177(346)$ & $177(346)$ & $177(346)$ & 177 \\
Mean, $P_{m}$ & $1.12(1.19)$ & $1.24(1.28)$ & $1.10(1.17)$ & 1.04 \\
COV, $V_{p}$ & $0.110(0.251)$ & $0.123(0.250)$ & $0.092(0.169)$ & 0.086 \\
$\phi$ & 0.90 & 0.85 & 0.91 & --- \\
$\beta$ & $2.86(2.32)$ & $3.28(2.61)$ & $2.69(2.54)$ & -- \\
$\phi_{2}$ (direct comparison) & 0.90 & 0.90 & 0.90 & 0.90 \\
$\beta_{2}$ (direct comparison) & $2.86(2.32)$ & $3.19(2.54)$ & $2.83(2.67)$ & 2.50 \\
\hline
\end{tabular}

Note that only 177 specimens are within the limit of applicability of the CSM, while a total of 346 tests are covered by the three international specifications. Values in brackets refer to the full database of 346 tests. 


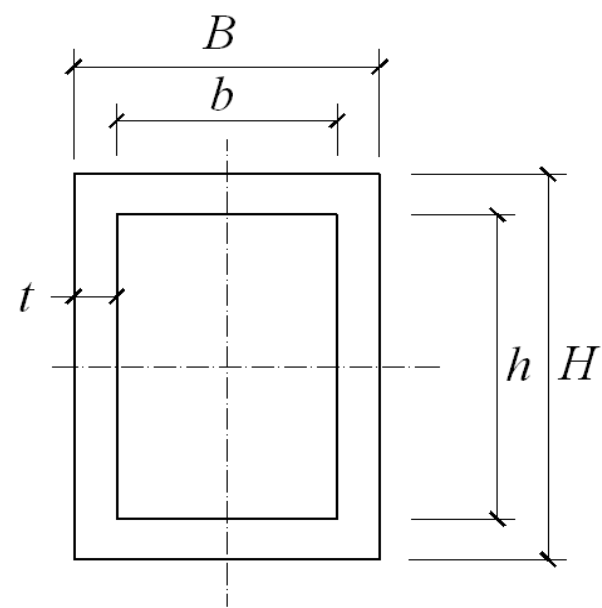

Fig. 1. Definition of symbols for SHS/ RHS with all elements of thickness $t$

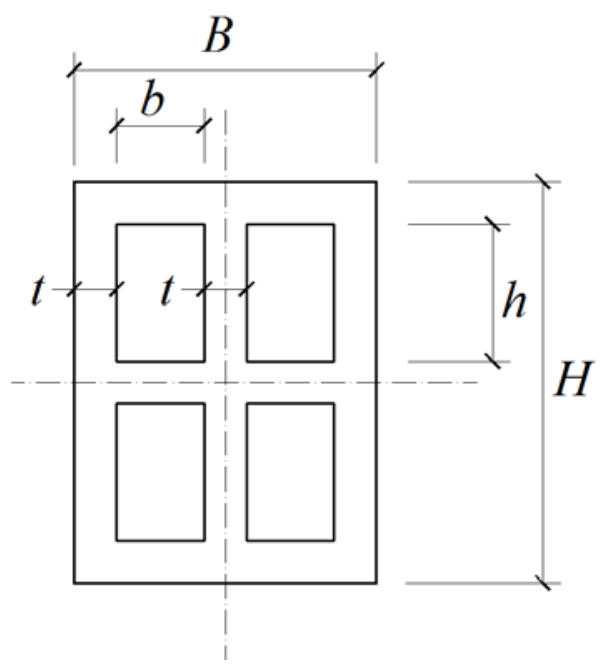

Fig. 2. Definition of symbols for SHS/RHS with internal cross stiffeners with all elements of thickness $t$ 


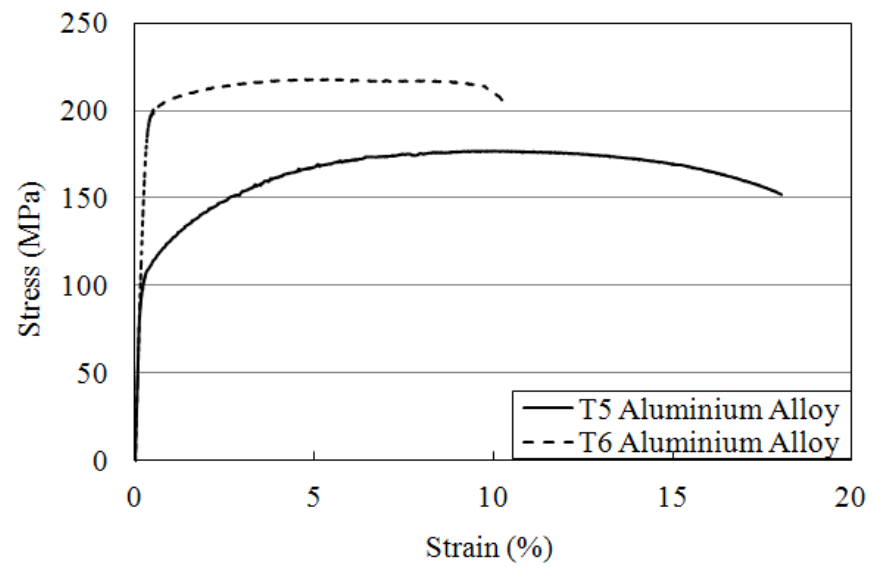

Fig 3. Static stress-strain curves for T5 (normal-strength) and T6 (high-strength) material

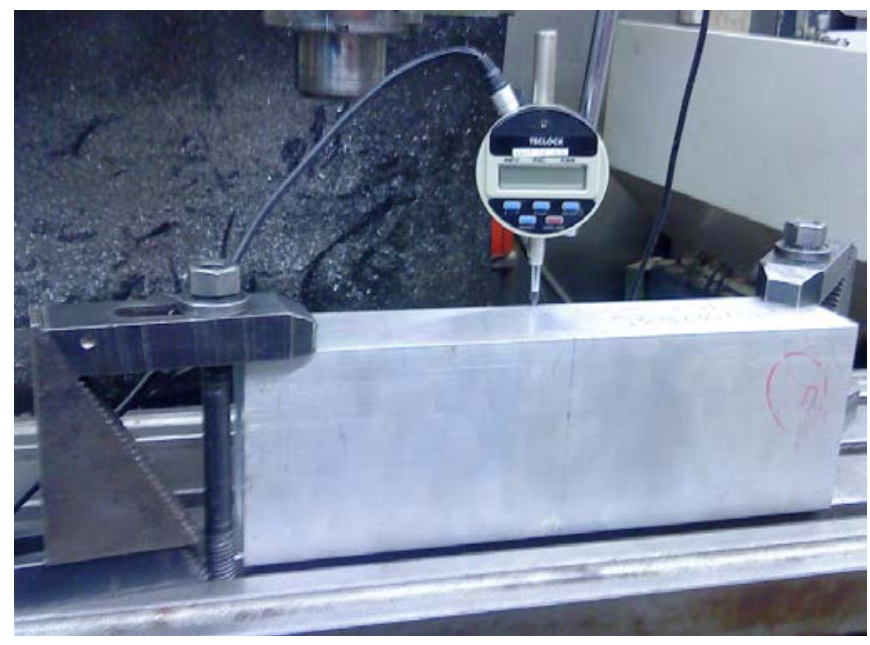

Fig. 4. Measurement of initial local geometric imperfections 


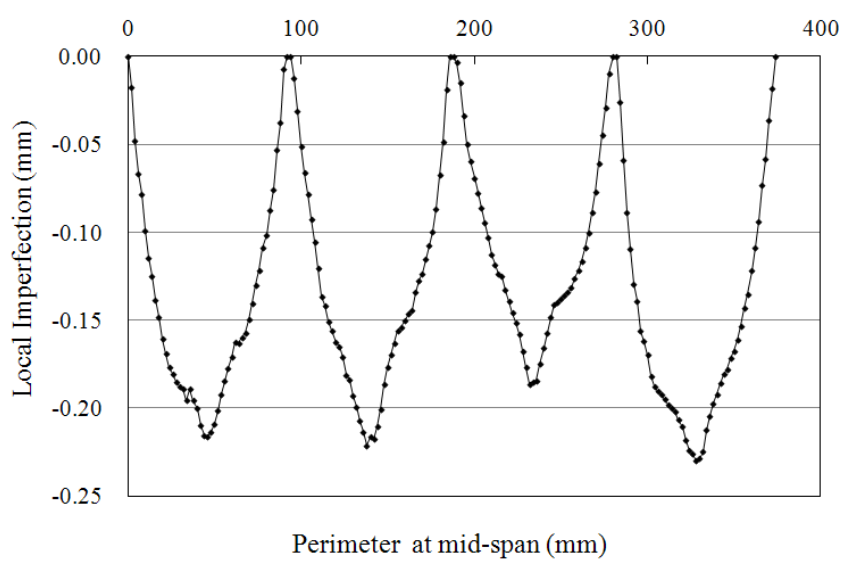

Fig. 5. Initial local geometric imperfection profile around perimeter of specimen $+H 95 \times 95 \times 4.3 \mathrm{C}-\mathrm{R}$

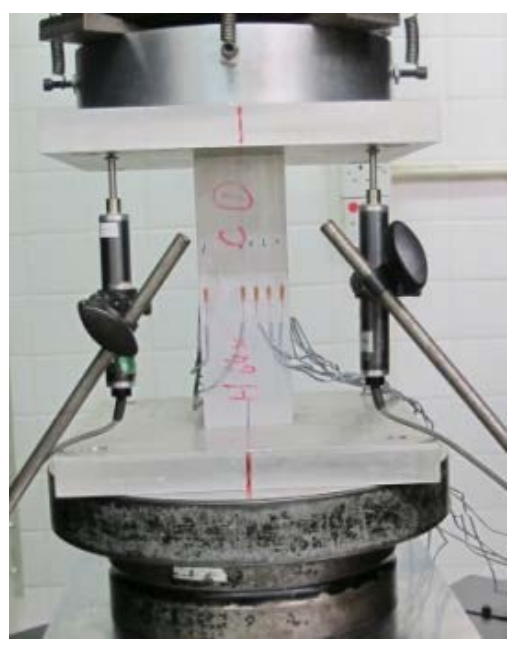

Fig. 6. Stub column test configuration, shown for specimen $\mathrm{H} 70 \times 55 \times 4.2 \mathrm{C}$ 


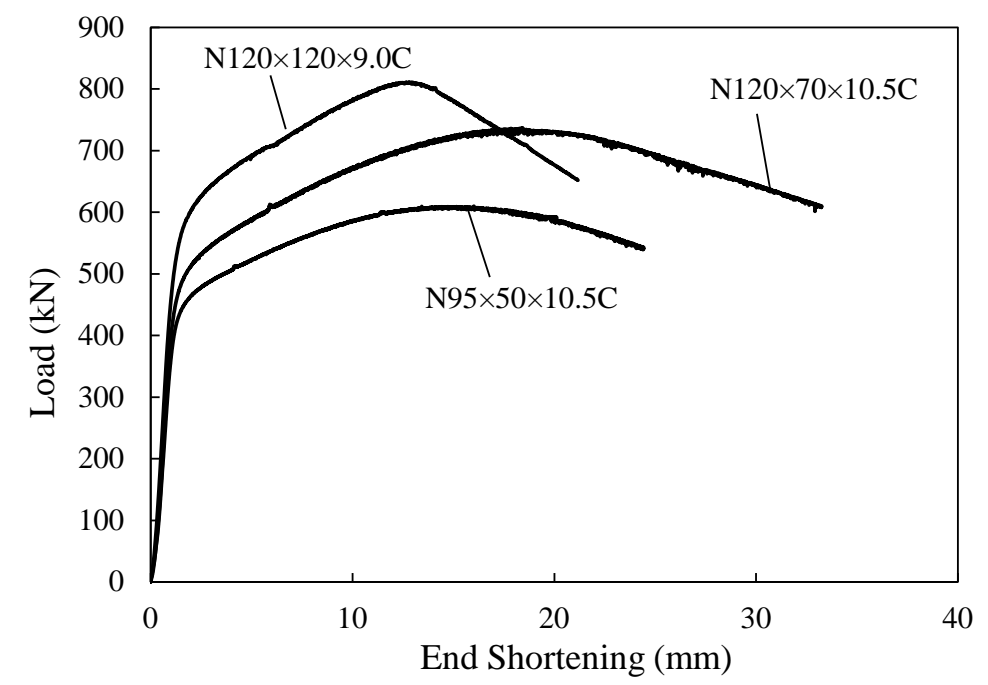

Fig. 7. Load-end shortening curves for stub columns (Temper 6063-T5)

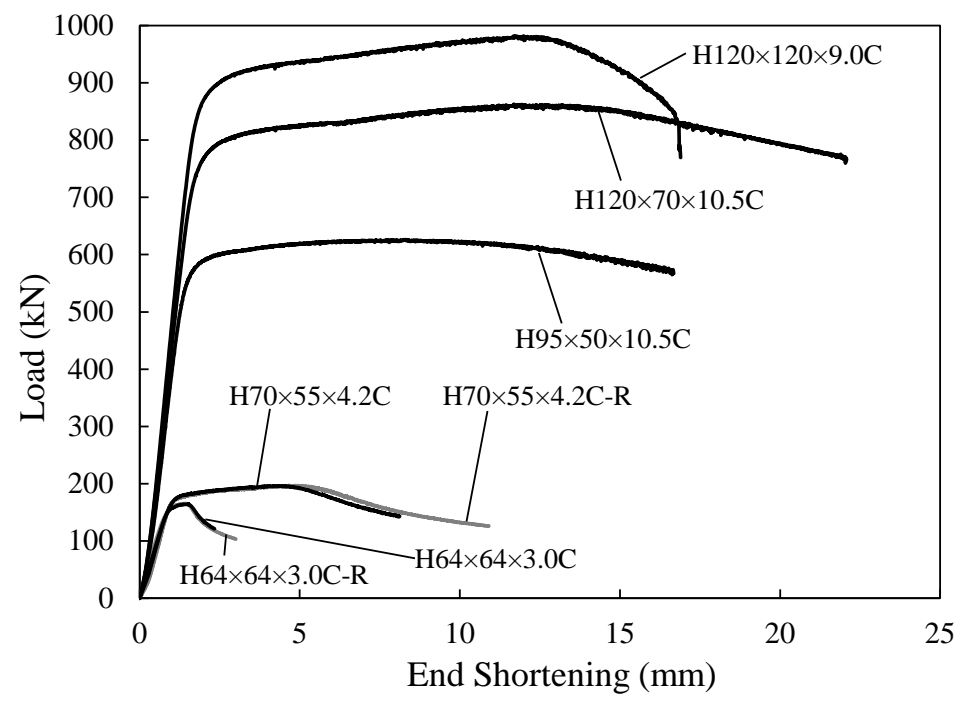

Fig. 8. Load-end shortening curves for stub columns (Temper 6061-T6) 


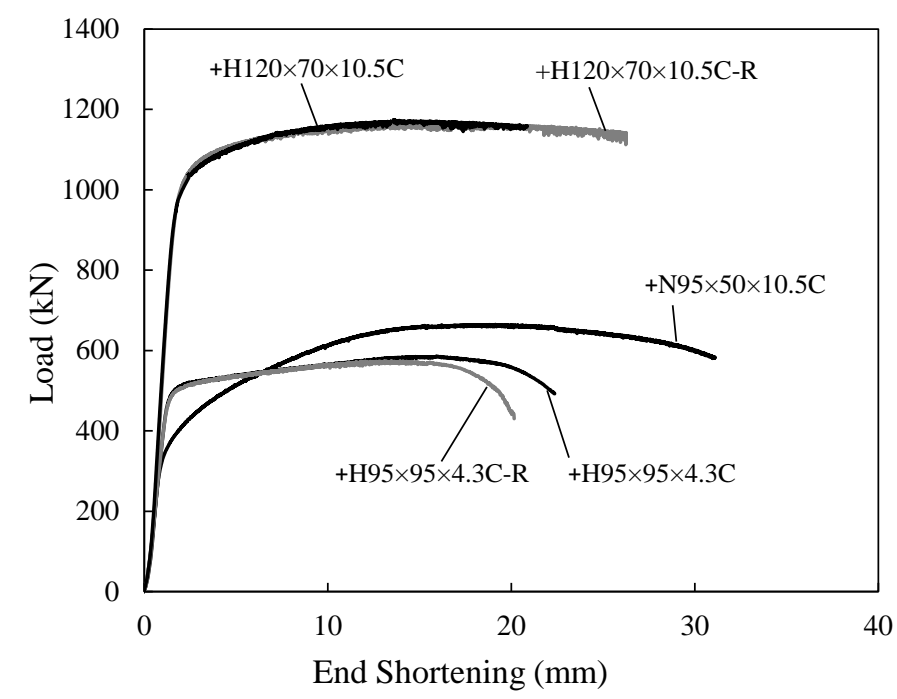

Fig. 9. Load-end shortening curves for stub columns (with internal cross stiffeners)

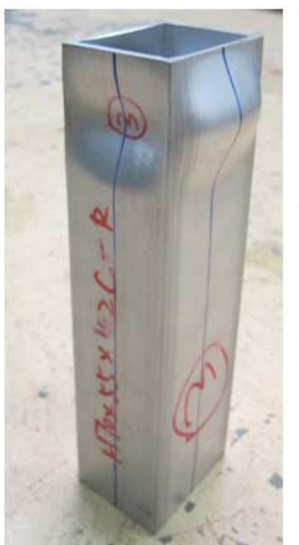

(a)

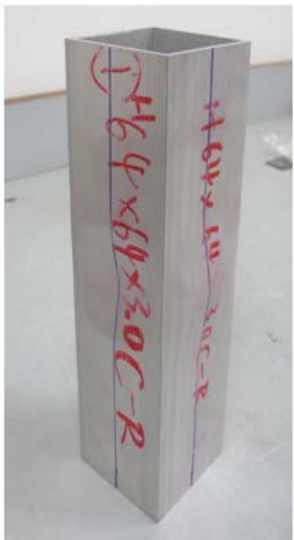

(b)

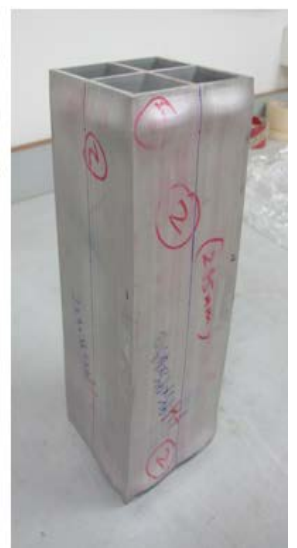

(c)

Fig. 10. Stub column failure modes for specimens (a) $\mathrm{H} 70 \times 55 \times 4.2 \mathrm{C}-\mathrm{R}$, (b) $\mathrm{H} 64 \times 64 \times 3.0 \mathrm{C}-\mathrm{R}$ and (c) $+\mathrm{H} 95 \times 95$ $\times 4.3 \mathrm{C}$ 


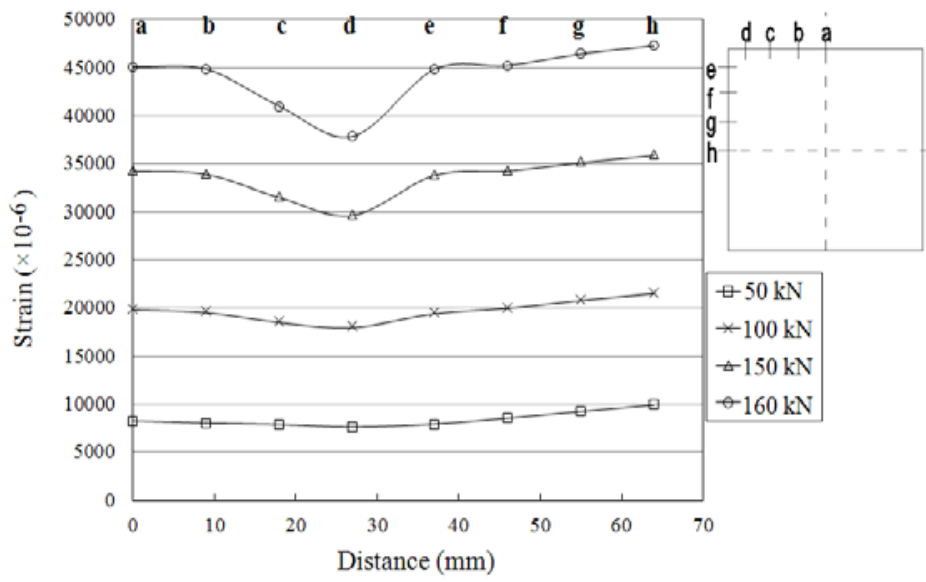

Fig. 11. Strain distribution around one quarter of the cross-section for specimen $\mathrm{H} 64 \times 64 \times 3.0 \mathrm{C}$ at various load levels

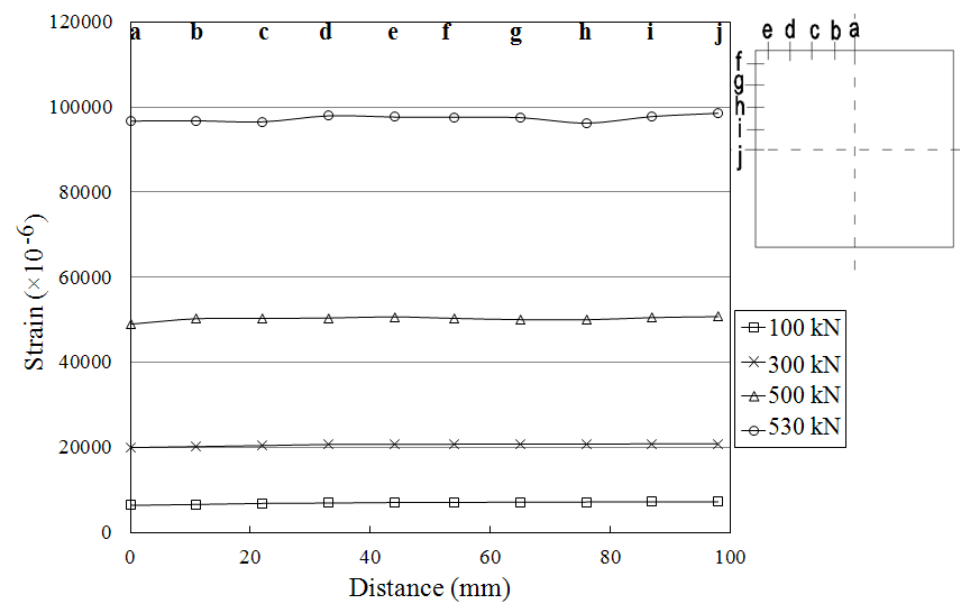

Fig. 12. Strain distribution around one quarter of the cross-section for specimen $+\mathrm{H} 95 \times 95 \times 4.3 \mathrm{C}$ at various load levels 


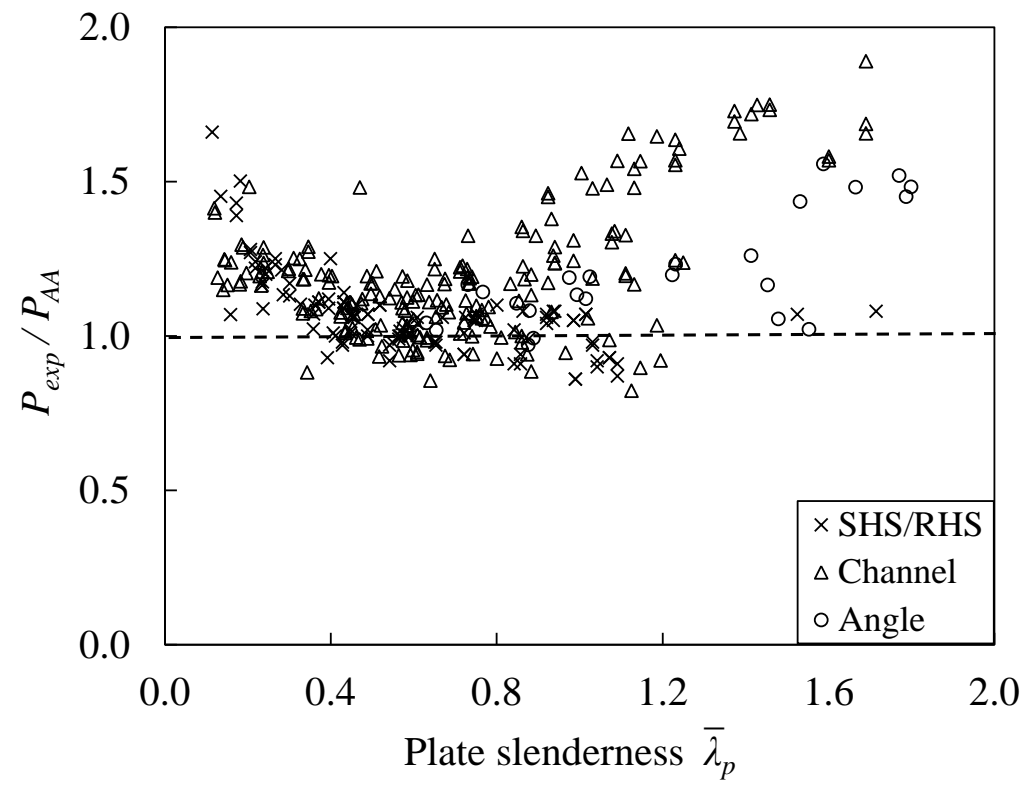

Fig. 13. Comparison between experimental results and design strengths predicted by the Aluminum Design Manual (AA, 2010)

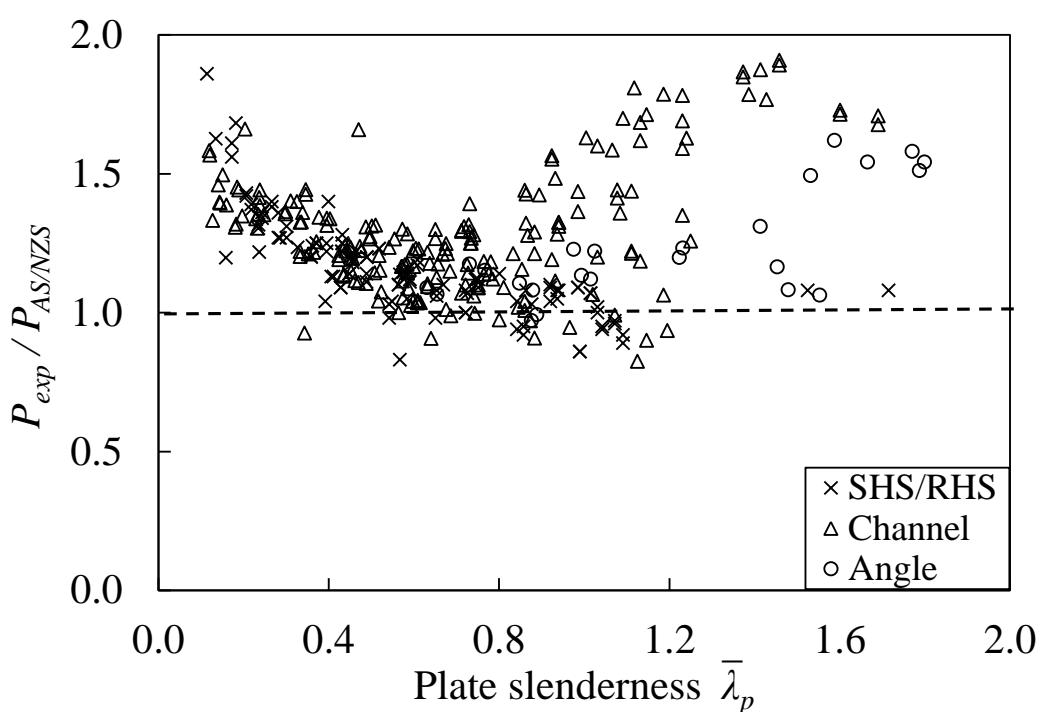

Fig. 14. Comparison between experimental results and design strengths predicted by the Australia/New Zealand Standard (AS/NZS, 1997) 


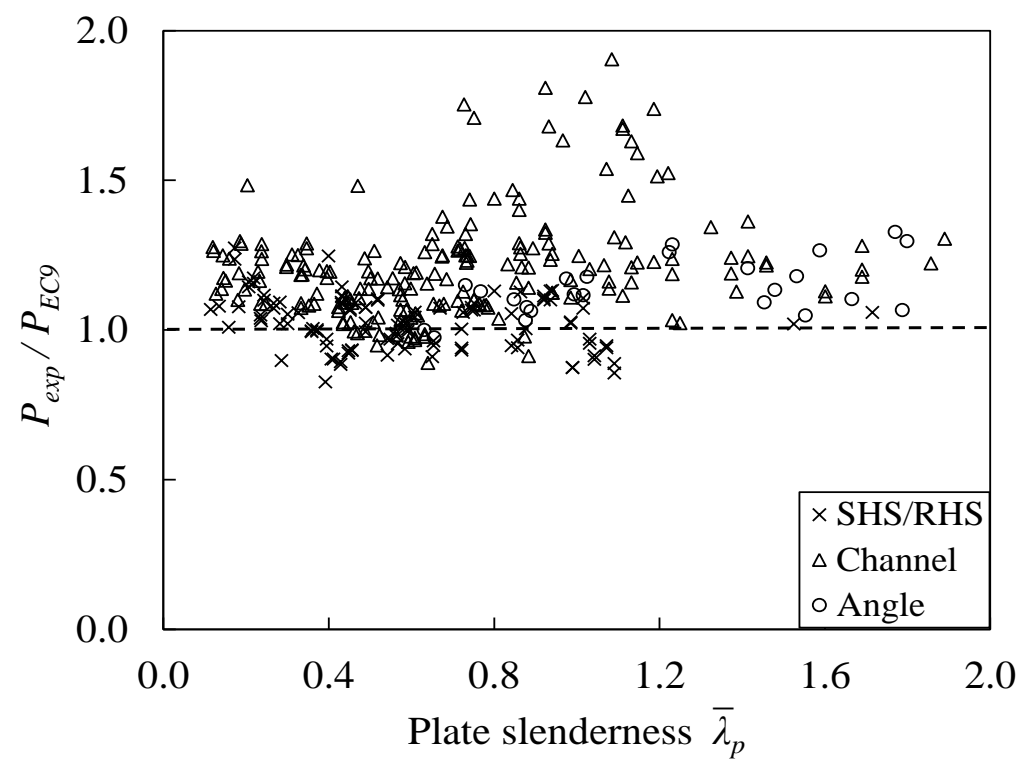

Fig. 15. Comparison between experimental results and design strengths predicted by Eurocode $9($ EC9, 2007)

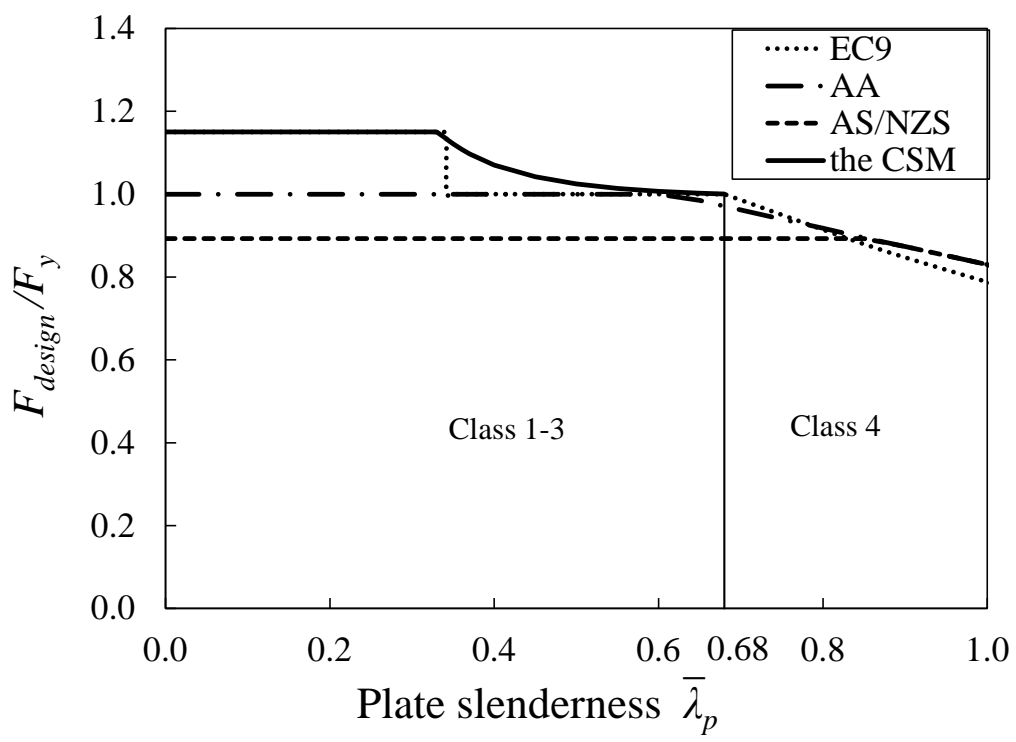

Fig. 16. Curves indicating design capacities of different design approaches for stub columns 


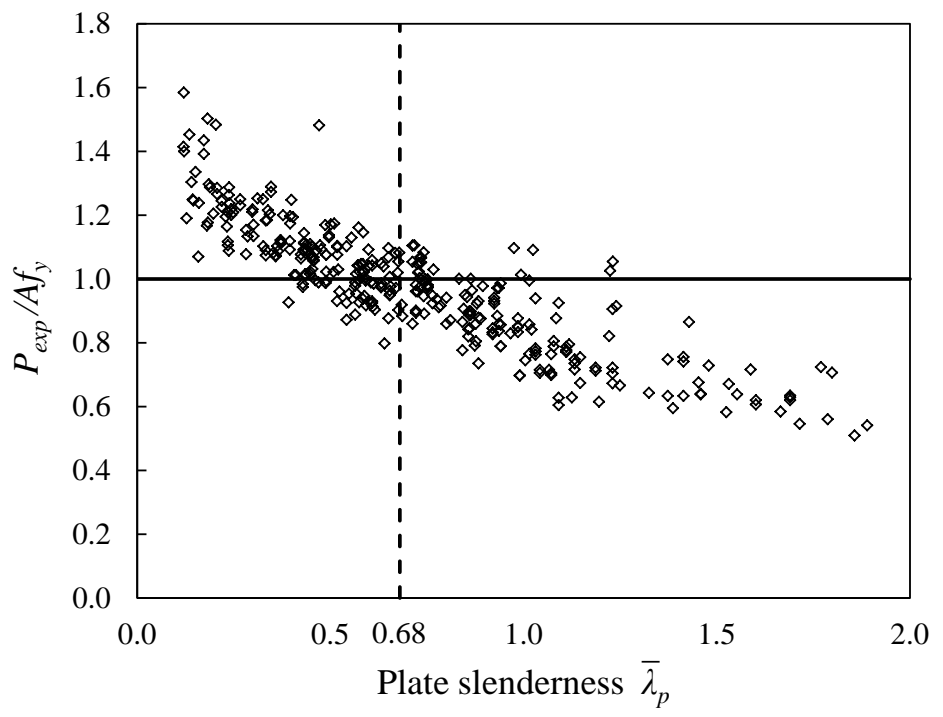

Fig.17: Comparison of 346 stub column test results with yield limit.

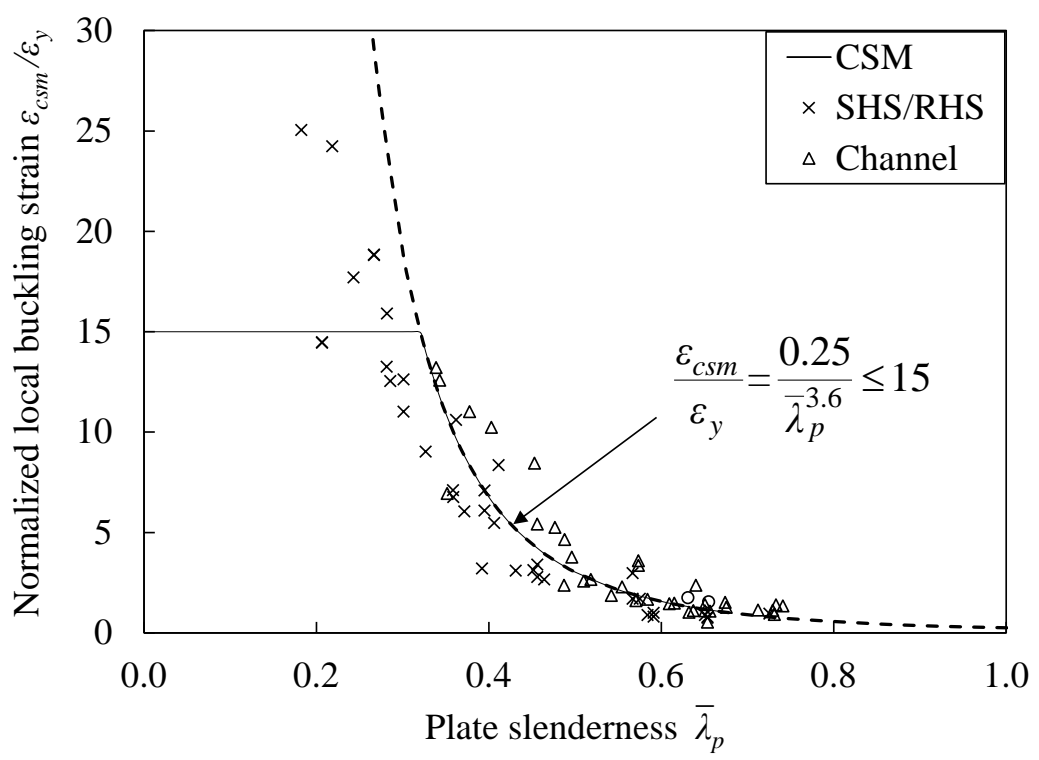

Fig. 18. Comparison between test results and the CSM design base curve 


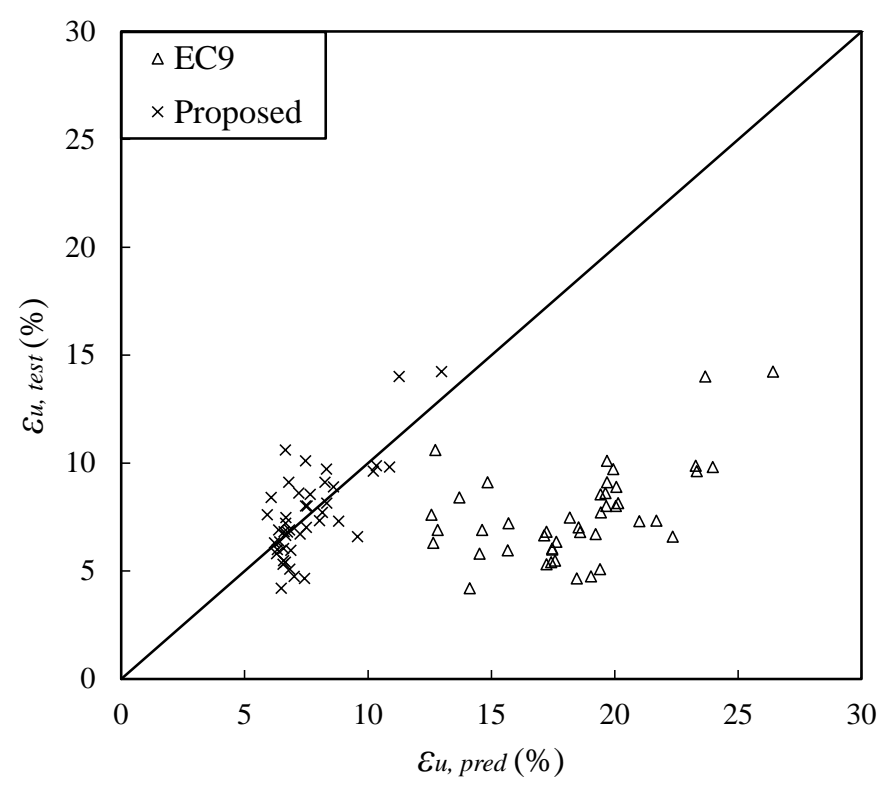

Fig. 19: Test versus predicted ultimate strain

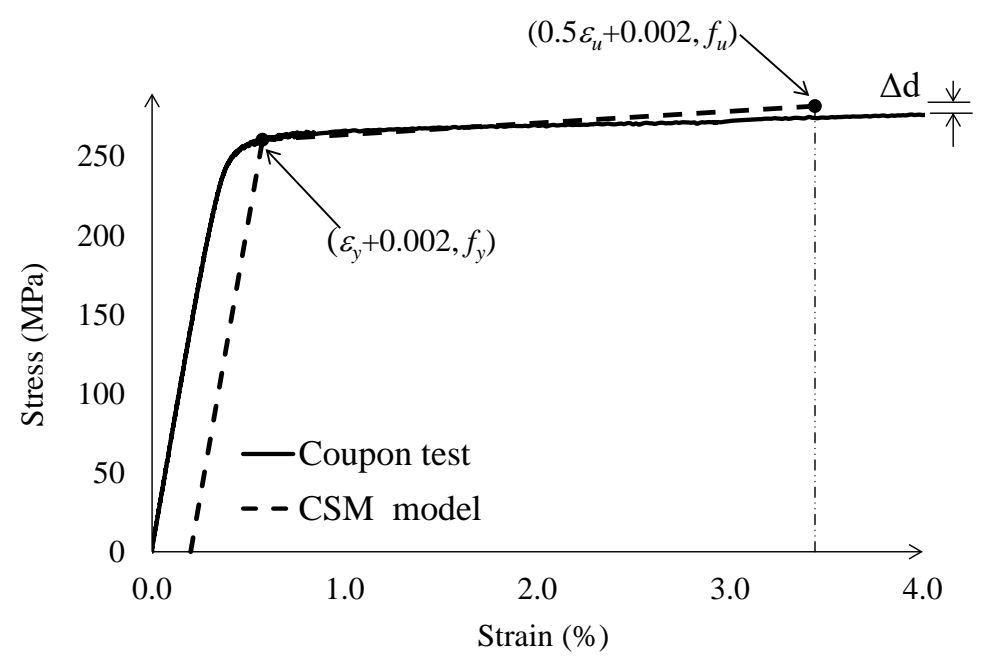

Fig. 20: Measured stress-strain curve and the CSM bi-linear material model for a typical specimen 


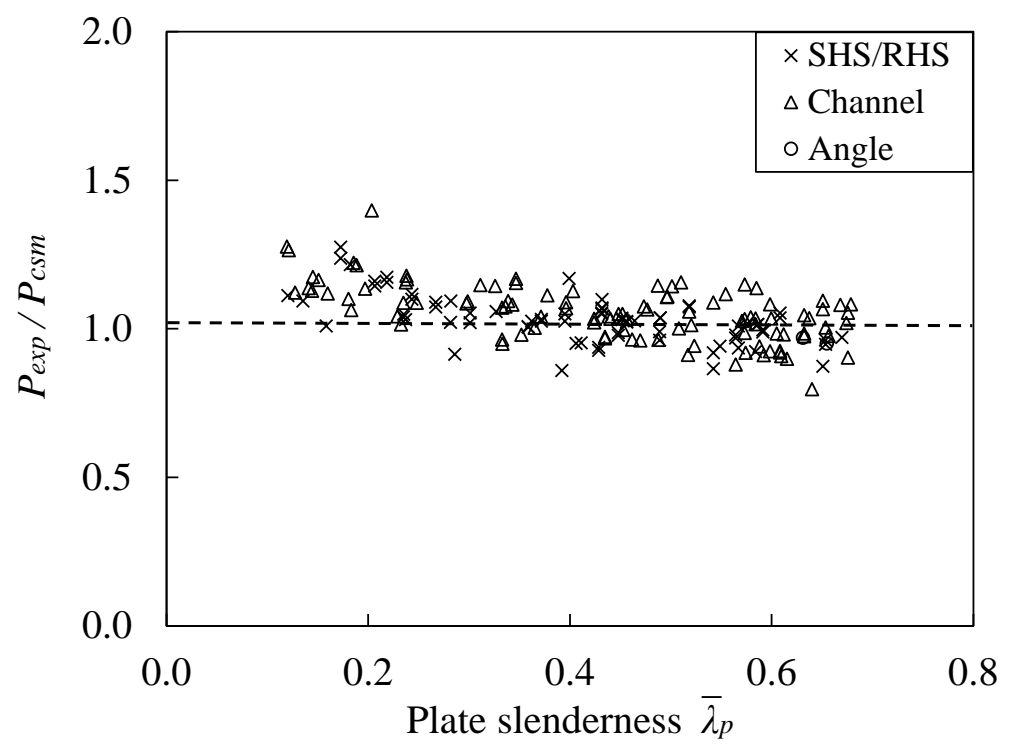

Fig. 21. Comparison between experimental results and design strengths predicted by the CSM 